Working Paper/Document de travail 2014-2

\title{
It Hurts (Stock Prices) When Your Team Is About to Lose a Soccer Match
}

by Michael Ehrmann and David-Jan Jansen 
Bank of Canada Working Paper 2014-2

January 2014

\title{
It Hurts (Stock Prices) When Your Team Is About to Lose a Soccer Match
}

\author{
by \\ Michael Ehrmann ${ }^{1}$ and David-Jan Jansen ${ }^{2}$ \\ 1International Economic Analysis Department \\ Bank of Canada \\ Ottawa, Ontario, Canada K1A 0 G9 \\ mehrmann@bankofcanada.ca \\ 2De Nederlandsche Bank, Economics and Research Division \\ Amsterdam, The Netherlands \\ Corresponding author: d.jansen@dnb.nl
}

Bank of Canada working papers are theoretical or empirical works-in-progress on subjects in economics and finance. The views expressed in this paper are those of the authors.

No responsibility for them should be attributed to the Bank of Canada, de Nederlandsche Bank or the Eurosystem. 


\section{Acknowledgements}

We thank Maarten Bosker, Mark Mink, Maarten van Oordt, seminar participants at the University of Groningen and de Nederlandsche Bank, and the audience at the 2012 EEA Meetings, in particular Michael Haliassos, for thoughtful feedback. Any errors and omissions are our responsibility. 


\begin{abstract}
The end result of major sporting events has been shown to affect next-day stock returns through shifts in investor mood. By studying the soccer matches that led to the elimination of France and Italy from the 2010 FIFA World Cup, we show that moodrelated pricing effects can materialize as sporting events unfold. We do this by using intraday stock prices for a firm cross-listed on the Paris and Milan stock exchanges. This strategy allows for a straightforward identification of pricing effects. During the soccer matches, stock prices in the country that eventually loses are lower by up to seven basis points. The probability of underpricing increases as elimination from the tournament becomes more likely.

JEL classification: G02, G12, G14, G15

Bank classification: Asset pricing; Financial markets
\end{abstract}

\title{
Résumé
}

Il a été démontré que les résultats de grandes compétitions sportives obtenus un certain jour ont une incidence sur les rendements boursiers du lendemain, à cause des changements d'humeur des investisseurs. En étudiant les matches qui ont conduit à l'élimination de la France et de l'Italie de la Coupe du monde de football de 2010, les auteurs montrent que les changements d'humeur des investisseurs peuvent influer sur les cours au fil même des compétitions. Pour ce faire, ils exploitent les prix intrajournaliers des actions d'une entreprise cotée à la fois à la Bourse de Paris et à celle de Milan. Cette stratégie permet de repérer facilement les effets sur les prix. Pendant les matches, les cours de l'action étudiée peuvent être jusqu'à sept points de base en retrait dans le pays qui est sur le point de perdre. La probabilité de sous-évaluation augmente en même temps que se profile l'élimination de l'équipe nationale du tournoi.

Classification JEL : G02, G12, G14, G15

Classification de la Banque : Évaluation des actifs; Marchés financiers 


\section{Introduction}

This paper shows how a major shift in investors' emotions, caused by a national team's imminent elimination from a major sporting event, can almost instantaneously affect stock prices. In presenting these findings, this paper contributes to the continuing debate on the efficiency of financial markets and the rationality of market participants. In the aftermath of the 2007-09 global financial crisis, this debate has only intensified, with contributions from a wide range of academics, policy-makers, market participants and journalists. The 2013 Nobel Prize in Economics awarded for the empirical analysis of asset prices further underlines the relevance and importance of this debate ${ }^{1}$

As Baker and Wurgler (2007) discuss in their survey on investor sentiment, since at least the 1980s, researchers have explored the idea that investors can deviate from rationally discounting the stream of expected future cash flows. Early contributions include Shiller (1981), De Bondt and Thaler (1985), and DeLong et al. (1990). One segment of the literature has focused on so-called "investor mood": the effects of exogenous swings in human emotions on stock prices (Baker and Wurgler 2007, 136). Seminal contributions on investor mood investigate the effects of changes in daylight savings time (Kamstra, Kramer and Levi 2000), variations in the amount of morning sunshine (Hirshleifer and

\footnotetext{
${ }^{1}$ The 2013 Sveriges Riksbank Prize in Economic Sciences in Memory of Alfred Nobel was awarded to Eugene Fama, Lars Peter Hansen and Robert Shiller. For the announcement, see www.nobelprize.org. URL last visited November 2013.
} 
Shumway 2003) and seasonal affective disorder (Kamstra, Kramer and Levi 2003).

Recently, the end result of sporting events has been identifed as another relevant shifter of investor mood. Using a sample of 5,000 Dutch households, Kaplanski et al. (2013) find that the recent performance of individuals' favourite sports team significantly affects their stock market expectations. Agarwal, Duchin and Sosyura (2012) find that loan officers' decisions are sensitive to, among other things, outcomes of key sporting events. Regarding soccer matches, Edmans, García and Norli (2007) show that losing a World Cup elimination match lowers next-day stock returns by 49 basis points. An analogous effect is also present, although smaller in magnitude, after international cricket, rugby and basketball matches. Kaplanski and Levy (2010) find that these mood effects spill over into the U.S. stock market, owing to the influence of international investors.

Using soccer matches during the 2010 FIFA World Cup, this paper shows that investor mood begins to evolve during sporting events, in contrast to the previous literature, which has focused on the effect of the final scoreline. As the soccer game progresses and the scoreline develops, the match outcome becomes increasingly predictable. For instance, if a soccer team is trailing by one goal with only a few minutes left to play, it is unlikely that the team will win the match $2^{2}$ By that time, the mood of the supporters of the team that is

\footnotetext{
${ }^{2}$ It would not be without precedent, though. One notable case is the 1999 Champions League final, when Manchester United scored two goals in injury time to beat Bayern Munich
} 
about to lose will already have soured.

Methodologically, our paper combines three distinctive features. First, we focus on investor mood during international soccer matches using intraday data. As argued by Edmans, García and Norli (2007), soccer results are appealing measures of investor mood. In many countries, a large portion of the population intensively follows and passionately discusses soccer. However, evaluating the contemporaneous effects of soccer results on mood and price formation is not straightforward. High-profile international soccer matches often take place in the evenings or during weekends, when markets are closed. Also, for matches that do coincide with trading hours, intraday data is less readily available than daily data. Accordingly, papers typcially study shifts in mood using daily returns for the day after the match (Edmans, García and Norli 2007; Kaplanski and Levy 2010) $]^{3}$ In contrast, we study minute-by-minute data during the 2010 FIFA World Cup, a major sporting event that has attracted a lot of attention, even during trading hours (Ehrmann and Jansen 2012).

A second distinctive feature of this paper is the use of trading information for a cross-listed company, STMicroelectronics, which is included in the main index of both the Milan and Paris stock exchanges. For cross-listed stocks, in principle, the prices on both exchanges should be equal, since the stocks by $2-1$.

${ }^{3}$ Croxson and Reade (2013) use high-frequency data from sports betting markets to study market efficiency. They find that prices update fully and swiftly in response to soccer goals. 
entail the same rights to the company's expected cash flows. Accordingly, we use deviations from the parity between prices on the Milan and Paris stock exchanges to measure pricing anomalies. Since we can use only a limited number of matches during the 2010 World Cup, we have, in contrast to standard event studies, the considerable advantage of not having to rely on a particular model to determine abnormal stock returns (MacKinlay 1997).

The third distinctive feature is the paper's focus on two particularly eventful matches, in which two high-profile soccer nations were rather unexpectedly eliminated from the tournament. By using a stock that is traded in Milan and Paris, we naturally focus our attention on matches in which either Italy or France participated. Both nations have an impressive soccer tradition, and expectations were high for the 2010 World Cup. After all, Italy was the defending champion, having beaten France on penalties in the 2006 final. However, the 2010 tournament did not go well for either team: neither managed to qualify for the second stage. We focus on the two matches in the group stage that resulted in the elimination of France and Italy, expecting mood effects to be particularly severe, in line with Edmans, García and Norli (2007).

This paper is based on a small sample, by focusing on only one stock and two matches, although the use of minute-by-minute data enables us to run sensible statistical tests. While a larger sample would be preferable, this is not straightforward. As mentioned, in most cases, the scheduling of soccer matches does not coincide with stock market trading hours, and high-frequency stock 
market data are less widely available than daily stock market data. In addition, few cross-listed companies have a large market capitalization on several exchanges, which furthermore are open during the matches.

This paper shows that sporting events can affect stock pricing via mood effects and provides detailed insight into the evolution of these effects. We present four pieces of evidence. First, stock prices in the country whose national team is losing its match are significantly below those in the other stock market, with a frequent gap of up to seven basis points. Second, the probability of underpricing increases as the match unfolds and the elimination of the team becomes more likely. Third, in case of the match between South Africa and France, such an effect arises only after France is trailing. Finally, for that same match, the mood effect is still visible at the start of the next trading day. This last finding is in line with Edmans, García and Norli (2007), although the effect is less pronounced in our estimations. To ensure that we are capturing soccer-related mood effects, we construct placebo samples and verify that, for these, no comparable pricing gaps occur.

\section{Description of the soccer matches}

We study mood-related pricing effects during two soccer matches at the 2010 FIFA World Cup, namely the last matches of France and Italy in the group 
stage 4 Despite the high expectations that were held against the two teams (Italy having won the previous edition of the World Cup, and France having come second), both teams had started off poorly in the tournament. In Group A, France had tied against Uruguay and lost against Mexico. Ahead of the match with South Africa, there were scenes of discord between French players and coaches.5 In Group F, Italy had tied against both Paraguay and New Zealand. For the final match of the group stage, Italy, but even more so France, needed a solid result to progress to the second round of the tournament.

On 22 June, France and South Africa met for their final match in the group stage. Not only France, but also South Africa would have to win the match in order to make it to the knock-out stage. Furthermore, both teams depended on the result of the other match in Group A between Mexico and Uruguay, which was being played simultaneously. In the 20th minute, South Africa took the lead, before scoring again to take a 2-0 lead in the 37th minute. Given the scoreline, and the fact that France was playing with only 10 men after Yoann Gourcuff was sent off in the 25th minute, it looked unlikely that France would qualify for the next round. When Uruguay took the lead in the 43rd minute of its game, France would have needed five goals in order to qualify. South

\footnotetext{
${ }^{4}$ For information on these two soccer matches, see the FIFA website. URL last visited July 2013. The other matches played by Italy and France at the 2010 World Cup took place outside trading hours.

${ }^{5}$ See, for instance, the BBC report "France boycott training over Anelka row", 20 June 2010, on the BBC website, URL last visited November 2013.
} 
Africa was the team with a small, but not unrealistic chance of progressing. In the 70th minute, French forward Florent Malouda managed to score a goal, but the game ended in a 2-1 victory for South Africa. France, the runner-up in the previous World Cup, left the tournament without winning a single game.

Slovakia and Italy met two days later in Johannesburg for their final match in Group F. For Italy, a draw would ensure progressing to the next round, as long as Paraguay beat New Zealand. However, Slovakia started the game in better fashion. The Slovakians had two solid chances in the first 15 minutes of the game, before taking the lead in the 24th minute. Just after the Milan stock exchange closed, Italy conceded a second goal. Since the game between Paraguay and New Zealand was tied, elimination of Italy from the World Cup seemed imminent. The final minutes of the match were spectacular, with three late goals. The final result, a 3-2 win for Slovakia, abruptly ended Italy's campaign to defend the World Cup title.

\section{Methodology}

From the data set described in Ehrmann and Jansen (2012), we use minute-byminute data on the stock price of STMicroelectronics, as traded on the Paris and Milan stock exchanges between 3 May and 30 July 2010. The reason for this choice is that this stock is cross-listed on two exchanges that are both open for trading during the soccer matches. In addition, while being located in two different countries, both stock exchanges trade in the same currency, preventing 
the need to strip out the effects of high-frequency fluctuations in exchange rates. Furthermore, we prefer analyzing stocks with sufficient liquidity, which is why we restrict our attention to those included in a country's main stock market index. In the end, given these constraints, the analysis focuses on the stock of STMicroelectronics 6

STMicroelectronics is one of the world's largest semiconductor companies, with a revenue of close to US\$ 8.5 billion in 2012 . The company was created as SGS-THOMSON Microelectronics following a merger in 1987 and renamed STMicroelectronics in 1998. The company's stock has been publicly traded since 1994 and is included both in the Paris CAC 40 index and the Milan FTSE MIB index.7 Both the French and the Italian markets are liquid markets, with a median trade volume of around 4,300 trades per minute on the Paris exchange, and 5,500 on the Milan exchange.

We measure pricing anomalies as deviations from theoretical parity, as in De Jong, Rosenthal and Van Dijk (2009). For instance, from the perspective of the French market, we calculate the percentage deviation from log parity $\left(P D_{t}^{F}\right)$ as follows:

$$
P D_{t}^{F}=100 * \log \left(\frac{P_{t}^{\text {Paris }}}{P_{t}^{\text {Milan }}}\right)
$$

\footnotetext{
${ }^{6}$ From the stocks covered in Ehrmann and Jansen (2012), companies that we considered, but were not able to include for one or more of the reasons listed above, are ArcelorMittal, Petroleo Brasileiro, Reed Elsevier, Royal Dutch Shell and Unilever.

${ }^{7}$ Source: Company information on STMicroelectronics website, http://www.st.com, URL last visited July 2013.
} 
and, from the Italian perspective, the percentage deviation $\left(P D_{t}^{I}\right)$ as:

$$
P D_{t}^{I}=100 * \log \left(\frac{P_{t}^{\text {Milan }}}{P_{t}^{\text {Paris }}}\right)
$$

where $P_{t}^{\text {Paris }}$ is the price of the stock in Paris and $P_{t}^{\text {Milan }}$ is the price in Milan. On average, one would expect $P D_{t}^{F}$ and $P D_{t}^{I}$ to equal zero, since any price differences for STMicroelectronics stocks between the Paris and Milan exchanges would create arbitrage opportunities. ${ }^{8}$ A positive value for $P D_{t}^{F}$ indicates an overpricing of the stock in Paris, and a negative value an underpricing. A negative value for $P D_{t}^{I}$ denotes an underpricing of the stock in the Milan market. Accordingly, we would expect our deviation measures to turn negative if the investor mood turns sour during the respective soccer matches.

The sample period includes the period of the 2010 World Cup, which started on 11 June and ended on 11 July, as well as a benchmark sample six weeks before and three weeks afterward. In the raw data, the prices from the Milan exchange are rounded to half a euro cent, so we also round the prices for the Paris exchange. In calculating the price differences, there are some obvious outliers, to the order of 500 basis points. We exclude those observations from the analysis where the absolute price difference between Paris and Milan is larger than 1.5 euro cents, which roughly means that the largest observable relative price difference is around 25 basis points.

We first study evidence of mood effects using detailed graphs. To this end,

\footnotetext{
${ }^{8}$ However, for a sample of 12 dual-listed companies, De Jong, Rosenthal and Van Dijk (2009) find that simple trading rules give abnormal returns of up to $10 \%$ per year.
} 
we use time plots for pricing deviations as the match progresses. If mood effects are present, we expect the pricing deviations to turn negative as the matches progress, and elimination for France and Italy looks increasingly likely. Also, we use histograms to study the distribution of pricing deviations during and outside the matches. Compared with a carefully constructed control sample, we should observe a higher number of negative pricing deviations during the soccer matches, if mood effects exist.

Next, we further quantify the possible mood effects on mispricing. We use probit regressions as $P D_{t}$, although, theoretically, a continuous variable effectively takes on only a limited number of outcomes $!^{9}$ We first study whether there is any evidence of mood effects during the matches by using a dummy variable $\left(\right.$ Match $\left._{t}^{i}\right)$ that equals one during the soccer games. We then estimate for each country the following probit model:

$$
\operatorname{Pr}\left[U_{t}^{i}=1 \mid \boldsymbol{x}_{t}^{i}\right]=\Phi\left(\boldsymbol{x}_{t}^{i \prime} \boldsymbol{\beta}\right)
$$

where $i \in\{F, I\}, U_{t}^{i} \in\{0,1\}$ measures underpricing, so that it equals one if $P D_{t}^{i}<0, \Phi($.$) denotes the CDF for the normal distribution, and the vector$ $\boldsymbol{x}_{t}^{i}$ contains the variable $M a t c h_{t}^{i}$ as well as dummies capturing months, weeks, weekdays and minutes of the day. The regressions use the full sample of minuteby-minute observations for $U_{t}^{i}$ between 3 May and 30 July 2010, thus capturing a large control sample outside the World Cup.

\footnotetext{
${ }^{9}$ We also run ordered probit and least-squares models. The conclusions are comparable with those from the probit regressions. Results available upon request.
} 
Next, we estimate four variations of the probit model in equation 3 . First, we study whether there is evidence of significant deviations from parity close to, but not during, the matches by using dummies capturing pre-match and post-match event windows. A priori, one would expect no mispricing in the pre-match windows, since investor mood will not yet be affected by the match progress. However, for the post-match windows, following the results of Edmans, García and Norli (2007), the occurrence of a mood effect in the country that was eliminated from the tournament is to be expected. For the pre-match window, we use the 15 minutes before the game starts. For the post-match window, we use two blocks of 15 minutes in the first 30 minutes of trading during the next day.

Another variation of equation 3 takes liquidity into account. As shown in Ehrmann and Jansen (2012), investors can be less attentive during major sporting events, leading to a decline of market liquidity. Therefore, we control for fluctuations in trading activity by including the number of trades, both in Paris and Milan, as control variables in the regressions.

We then turn to a more refined analysis of how the mood effect materializes during the match. We replace the dummy Match $_{t}^{i}$ with a variable that captures the number of elapsed minutes after the start of the game. If sentiment worsens as the game progresses, and elimination looks increasingly probable, we would expect a negative effect for this variable. Finally, we distinguish between the period when the game is still a tie and the period when a team is trailing. We 
use two dummies to capture this dynamic: the first is equal to one as long as the game is tied; and the second equals one after the opponents score their first goal. If mood effects are present, one would expect them to materialize in particular after a team is trailing in the match.

\section{Data description}

To get a first impression of the behaviour of the stock prices on the Paris and Milan exchanges, we focus on the trading week between 21 and 25 June 2010, the week when both relevant soccer matches were taking place. Figure 1 plots the deviation from parity from the perspective of the Paris market, showing the average hourly value of $P D_{t}^{F}$. A positive value indicates overpricing on the Paris market and underpricing on the Milan market. A negative value for $P D_{t}^{F}$ indicates underpricing in Paris and overpricing in Milan. During this particular week, the stock for STMicroelectronics traded in the range of $€ 6.70$ and $€ 7.13$, with an average price of $€ 6.92$.

On Monday, 21 June, the average value of the pricing deviation per hour is small and fluctuates mostly between -0.02 and $0.02 \%$. On Tuesday, 22 June, the pattern is similar, up to the time when the match starts at 16:00. During the last half hour of trading, there is a sharp downward spike in the pricing deviation. When trading starts on the day after the match, the graph suggests a quick reversal in the first hour of trading. In fact, during the day, there seems to be, on average, a degree of overpricing in the Paris market. 
Turning to Thursday, 24 June, the day of the Italian match, we again see a spike in the pricing deviation at the end of the trading day, although less marked than on the preceding Tuesday. In this case, the overpricing in the Paris market corresponds to an underpricing in the Italian market during the Slovakia versus Italy match. Again, there is a quick correction as trading opens on Friday, 25 June. During that last day of trading in that week, mispricing again fluctuates between -2 and 2 basis points. These patterns provide the first supportive evidence for our hypothesis of a mood-related effect on stock prices during the soccer matches.

(insert Figure 1 about here)

\section{Mood effects: Evidence using graphs}

We now turn to more detailed evidence for mood effects. Figures 2 and 3 show the development of pricing deviations during the two soccer matches under study. The solid line shows percentage deviations from log parity in Paris (Figure 2) and Milan (Figure 3), for the time between 15:45 and the end of the trading day. The solid vertical lines indicate the game start at 16:00. The dotted vertical lines show relevant match events, such as goals by the opponent or red cards. We show 15-minute moving averages to facilitate readability of the graphs.

Before the match between France and South Africa, pricing deviations fluc- 
tuate between -2 and 2 basis points (Figure 2). This pattern continues during the first 20 to 30 minutes of the match, before becoming more volatile. We see increased evidence of underpricing after the South African goals and the red card for one of France's players, but especially during the last half hour of trading, in line with the evidence presented in Figure 1.

When the match between Italy and Slovakia starts, the prices in Milan are nearly equal to those in Paris (Figure 3). Quite soon, however, there is an underpricing of around 4 basis points, which widens abruptly to 6 basis points after the first Slovakian goal. During the remainder of the match, the stock in Milan trades a few basis points lower than the stock in Paris.

(insert Figures 2 and 3 about here)

Figure 4 provides a further perspective on mood effects during the soccer matches. Here, we plot the distribution of pricing deviations during the soccer matches (dark blue bars) and during a control sample outside the soccer matches (grey bars). The top histogram has results for the Paris exchange, while the bottom histogram summarizes deviations from the perspective of the Milan exchange. The control sample covers the period between 3 May 2010 and 30 July 2010, excluding the time frames of the two soccer matches. For France, the control sample uses only observations for Tuesdays from 16:00 until the Paris stock market closes. For Italy, the control sample uses only 
Thursdays, also from 16:00 until the end of trading. The vertical axis shows the percentage of the total number of observations.

The histograms show a clustering of the price deviations during the soccer matches around 7 and 14 basis points, which relates to the rounding of the raw stock prices to half a euro cent. During the French match, the average stock price of STMicroelectronics was $€ 6.98$ on the Milan exchange; thus, the smallest observable pricing deviation is around $0.072 \%$. The average price in Paris was $€ 6.80$ during the Italian match, so the smallest observable pricing deviation during this match is around $0.074 \%$. This is the reason why we rely on probit regressions rather than least-squares regresssion in the analysis.

The grey bars in Figure 4 indicate that, under normal circumstances, there are no pricing deviations in approximately $50 \%$ of the cases. Roughly $20 \%$ of the observations are clustered around -7 basis points, while around $20 \%$ are around +7 basis points. The remaining $10 \%$ of the deviations are clustered around 14 basis points, in absolute terms.

During the two soccer matches, negative price deviations are more prevalent than in the control sample. On the Paris stock market, the percentage of negative deviations around 7 basis points increases from around $20 \%$ to almost $40 \%$. At the same time, the number of positive deviations strongly decreases. The number of observations with no pricing deviation is comparable with the control sample. On the Milan stock exchange, there is underpricing of 7 basis points during the Italy match in close to half of the observations. Parity of 
prices in Paris and Milan occurs in only about $30 \%$ of the cases, while there are few instances of overpricing during the match between Slovakia and Italy.

(insert Figure 4 about here)

As a sensitivity analysis, we construct a placebo sample by assuming that the matches occurred one day earlier than they did. We use the time slots between 16:00 until trading ends on Monday, 21 June and Wednesday, 23 June. The control sample then uses the same time slot on all other Mondays (for France) and Wednesdays (for Italy). Figure 5 shows the histograms. Although there are some differences in the distributions of the blue and grey bars, there is no indication of a change comparable with that observed during the soccer matches 10

(insert Figure 5 about here)

\section{Mood effects: Evidence from probit models}

Tables 1 and 2 show marginal effects based on probit regressions to further analyze mood-related pricing effects related to soccer matches. Table 1 fo-

\footnotetext{
${ }^{10}$ We construct two additional placebo samples by assuming the matches occurred one week earlier or later. Figures available upon request. Estimation results for the three placebo samples will be discussed in Section 6 .
} 
cuses on the match between South Africa and France, using underpricing from the perspective of the Paris stock exchange as the dependent variable. Table 2 focuses on the match between Slovakia and Italy and shows results for the likelihood of underpricing from the Milan exchange perspective.

(insert Tables 1 and 2 about here)

Column 1 in tables 1 and 2, which shows only measures for the time of the match, provides the first evidence for a mood effect while the national team is losing its match, with underpricing 12.4 percentage points more likely during France's match against South Africa (Table 1) and 22.6 percentage points more likely during the Slovakia-Italy game (Table 2). There is strong statistical evidence that these estimated marginal effects are different from zero.

Next, we confirm the findings of Edmans, García and Norli (2007) that the mood effect can still be visible on the next trading day, although we find this effect only for the match between South Africa and France. During the first 15 minutes of trading on 23 June, there is still a 38.4-percentage-point greater likelihood of underpricing of STMicroelectronics' stock on the Paris exchange (Table 1, column 2). Based on the least-squares regressions (available upon request), we find that the average magnitude of the loss effect during the first quarter-hour of trading is around 7 basis points. This magnitude is smaller than the 49 basis points, measured as abnormal returns, reported in Edmans, 
García and Norli (2007) for World Cup elimination matches. Presumably, the smaller mood effect is related to the particular type of stock under study in our paper, for two reasons. First, because of the cross-listing, any arbitrage opportunities will be more salient, which may correct for the mood-induced pricing anomaly. Second, we are measuring stock prices against a stock market of a country, whose national team was also not doing particularly well. One might well imagine that the price gaps between the exchanges of a winning and a losing team's country are substantially larger. Unfortunately, the available data do not allow studying such a scenario.

Importantly, controlling for liquidity does not impact the qualitative findings (Tables 1 and 2, column 3). Including the number of trades, both on the Paris and Milan exchange, in the regression has no relevant effect on the estimated marginal effects, while the trade variables themselves are significant at the $5 \%$ level.

Turning to a more refined analysis of the relation between the match evolution and the mood effect, we find that the probability of observing underpricing increases as the two soccer games unfold. When using the number of minutes after the games start in the regressions, we find a negative and significant coefficient in the case of both matches (Tables 1 and 2, column 4). The estimated average marginal effects suggest that, relative to the degree of mispricing at the start of the game, each additional minute of playing time corresponds to an increased probability of underpricing by around half a percentage point. 
Finally, we ask when precisely the mood effect occurs during the match. In the case of the French match, we find that a negative mood effect is present only after France is trailing. After the first South African goal, there is a 20.2percentage-points greater probability of underpricing on the Paris exchange. As long as the game is tied, there is actually some evidence of a smaller likelihood of underpricing, although the coefficient is significant only at the $10 \%$ level (Table 1, column 5). For the Italian match, there is evidence of underpricing when the game is still tied (Table 2, column 5). The results for the French match are closely in line with our hypothesis that the mood effect will materialize when a team is trailing, especially if elimination from the tournament is increasingly likely. For the Italian match, it is less obvious why underpricing would already occur when the game is still a tie. However, the match reports suggest that Italy did not get off to a good start, and Slovakia had a number of good chances in the opening minutes of the game. The poor start may have had a negative effect on the investor mood in Italy.

We repeat the probit analyses using three placebo samples and find mostly insignificant effects. Table 3 summarizes these findings. Panel A shows results for the market in Paris; panel B shows results for the Milan stock exchange. The results in column 1 are based on the data shown in Figure 5, where we assume the matches took place one day earlier; column 2 assumes that matches took place one week later; and column 3 assumes that matches took place one week earlier. The marginal effects in Table 3 can be compared with those in 
column 1 of Tables 1 and 2. Most of the effects are estimated to be close to zero. In only one out of six cases, the marginal effect is significant at the $5 \%$ level (panel B, column 2). Still, the magnitude of the coefficient is less than half the size noted during the match between Slovakia and Italy.

(insert Table 3 about here) 


\section{Conclusions}

There is an ongoing and wide-ranging debate on the efficiency of financial markets and the rationality of market participants. This paper provides evidence that mood effects can affect stock pricing instantaneously and provides more insights into the evolution of these effects. By studying minute-by-minute stock prices during sporting events, we add to previous work that studies the effects of the final match outcome on next-day stock returns (Edmans, García and Norli 2007; Kaplanski and Levy 2010). The identification strategy applied in this paper also adds to the literature by using price information for a cross-listed firm.

Testing whether departures from market efficiency are present is not without challenges. This paper offers an intuitive example of how exogenous shocks to human emotions can affect stock pricing, even in a context where one would expect a high degree of price efficiency. As such, this paper offers food for thought about the operations of financial markets and the behaviour of market participants. In this context, extending the analysis to a larger sample of cross-listed firms during an extended set of matches will be instructive. It may also be interesting to investigate these mood effects using tick-by-tick rather than minute-by-minute data. This will increase the precision of the identification of mood effects during sporting events and thus shed further light on the degree of market efficiency. 


\section{References}

Agarwal, Sumit, Ran Duchin and Denis Sosyura. 2012. In the Mood for a

Loan: The Causal Effect of Sentiment on Credit Origination. Available at SSRN: http://ssrn.com/abstract=2141030.

Baker, Malcom and Jeffrey Wurgler. 2007. Investor Sentiment in the Stock Market. Journal of Economic Perspectives 21(2): 129-152.

Croxson, Karen and J. James Reade. 2013. Information and Efficiency: Goal Arrival in Soccer Betting. Economic Journal. Forthcoming.

De Bondt, Werner F. M. and Richard Thaler. 1985. Does the Stock Market Overreact? Journal of Finance 40(3): 793-805.

De Jong, Abe, Leonard Rosenthal and Mathijs A. Van Dijk. 2009. The Risk and Return of Arbitrage in Dual-Listed Companies. Review of Finance 13: 495-520.

DeLong, Bradford J., Andrei Shleifer, Lawrence H. Summers and Robert J. Waldmann. 1990. Noise Trader Risk in Financial Markets. Journal of Political Economy 98(4): 703-738. 
Edmans, Alex, Diego García and Øyvind Norli. 2007. Sports Sentiment and Stock Returns. Journal of Finance 62(4): 1967-1997.

Ehrmann, Michael and David-Jan Jansen. 2012. The Pitch Rather Than the Pit: Investor Inattention During FIFA World Cup Matches. European Central Bank Working Paper 1424.

Hirshleifer, David and Tyler Shumway. 2003. Good Day Sunshine: Stock Returns and the Weather. Journal of Finance 58(5): 1009-1032.

Kamstra, Mark J., Lisa A. Kramer and Maurice D. Levi. 2000. Losing Sleep at the Market: The Daylight Saving Anomaly. American Economic Review 90(4): 1005-1011.

Kamstra, Mark J., Lisa A. Kramer and Maurice D. Levi. 2003. Winter Blues: a SAD Stock Market Cycle. American Economic Review 93(1): 324-343.

Kaplanski, Guy and Haim Levy. 2010. Exploitable Predictable Irrationality: The FIFA World Cup Effect on the U.S. Stock Market. Journal of Financial and Quantitative Analysis 45(2): 535-553.

Kaplanski, Guy, Haim Levy, Chris Veld and Yulia Veld-Merkoulova. 2013. Do 
Happy People Make Optimistic Investors? Journal of Financial and Quantitative Analysis. Forthcoming.

MacKinlay, A. Craig. 1997. Event Studies in Economics and Finance. Journal of Economic Literature 35(1): 13-39.

Shiller, Robert J. 1981. Do Stock Prices Move Too Much to be Justified by Subsequent Changes in Dividends? American Economic Review 71(3): 421-36. 
Figure 1: Price deviations, Paris - Milan, between 21 and 25 June 2010

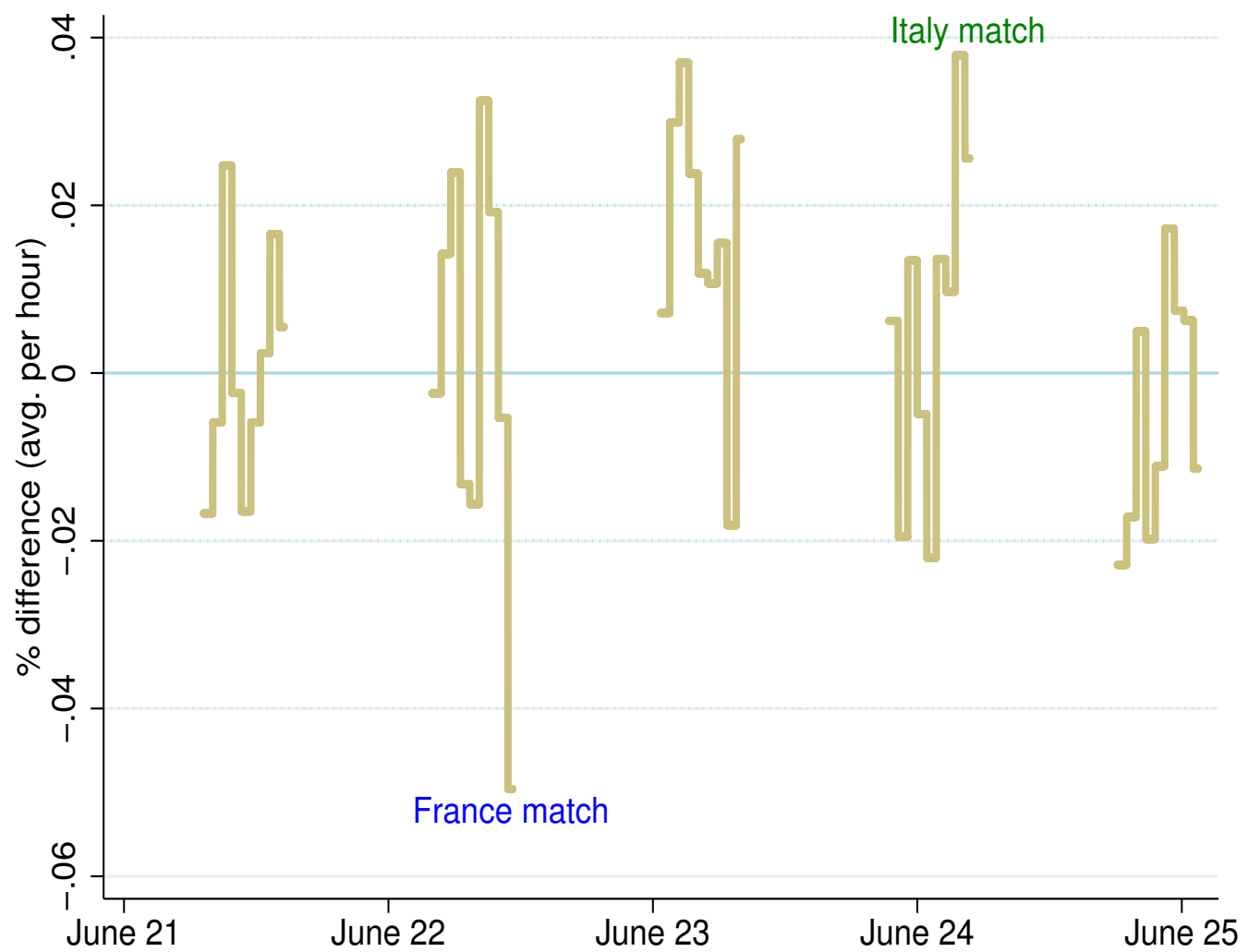

Notes: This figure shows pricing deviations for STMicroelectronics between the Paris and Milan stock exchange. The vertical axis shows average percentage deviations from log parity per trading hour. The deviations are computed as $P D_{t}^{F}$ following equation (1). The horizontal axis shows the trading week between 21 and 25 June 2010. 
Figure 2: Price deviations, Paris - Milan, during South Africa vs. France match

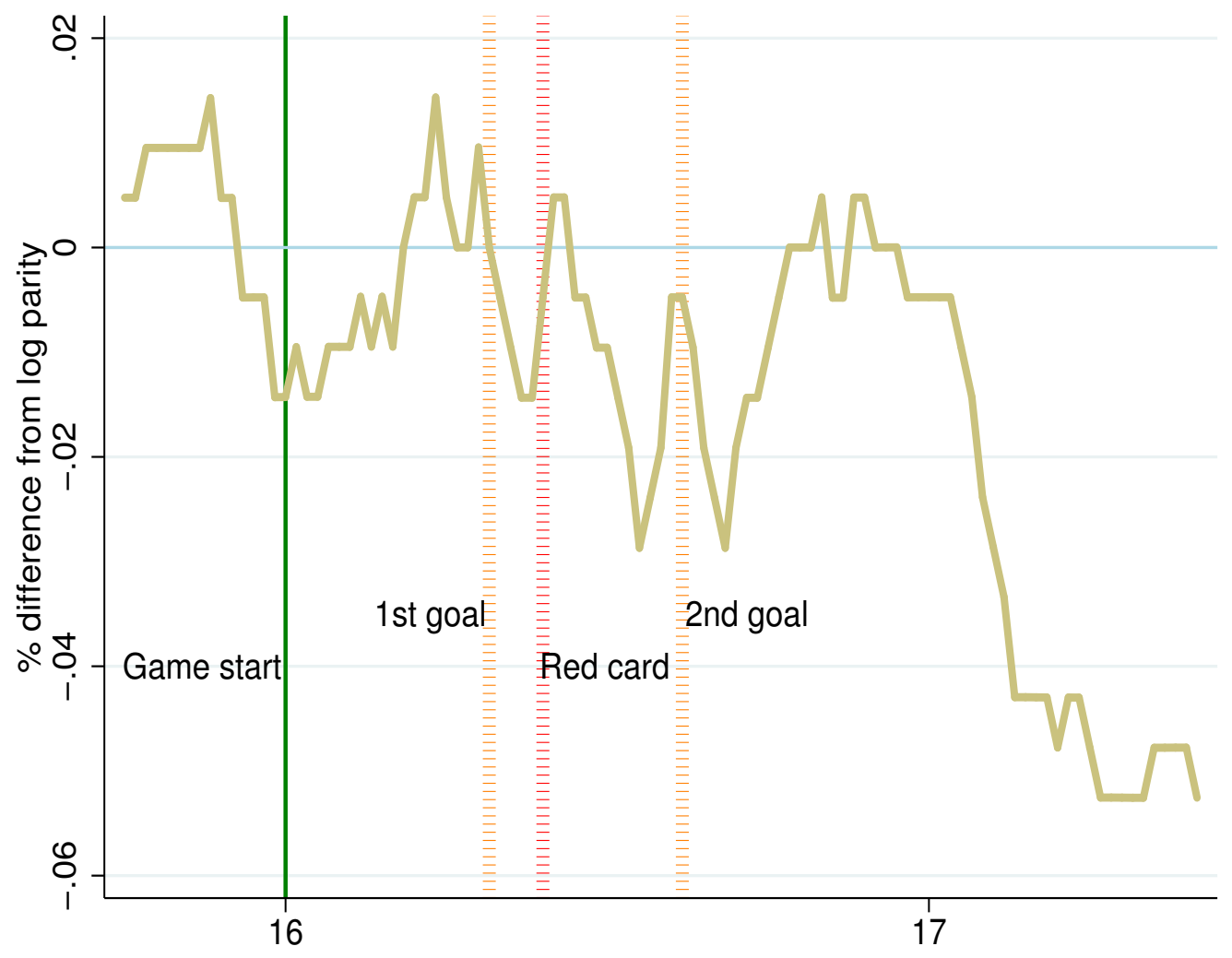

Notes: This figure shows percentage deviations from log parity between prices for STMicroelectronics on the Paris and Milan stock exchanges. We show 15-minute moving averages for $P D_{t}^{F}$ (equation 1) during the soccer match between South Africa and France on 22 June 2010 at the FIFA World Cup. The horizontal axis shows the period between 15:45 and 17:30. The solid vertical line denotes the start of the game at 16:00. The dotted vertical lines denote the two South African goals and the red card for France. 
Figure 3: Price deviations, Milan - Paris, during Slovakia vs. Italy match

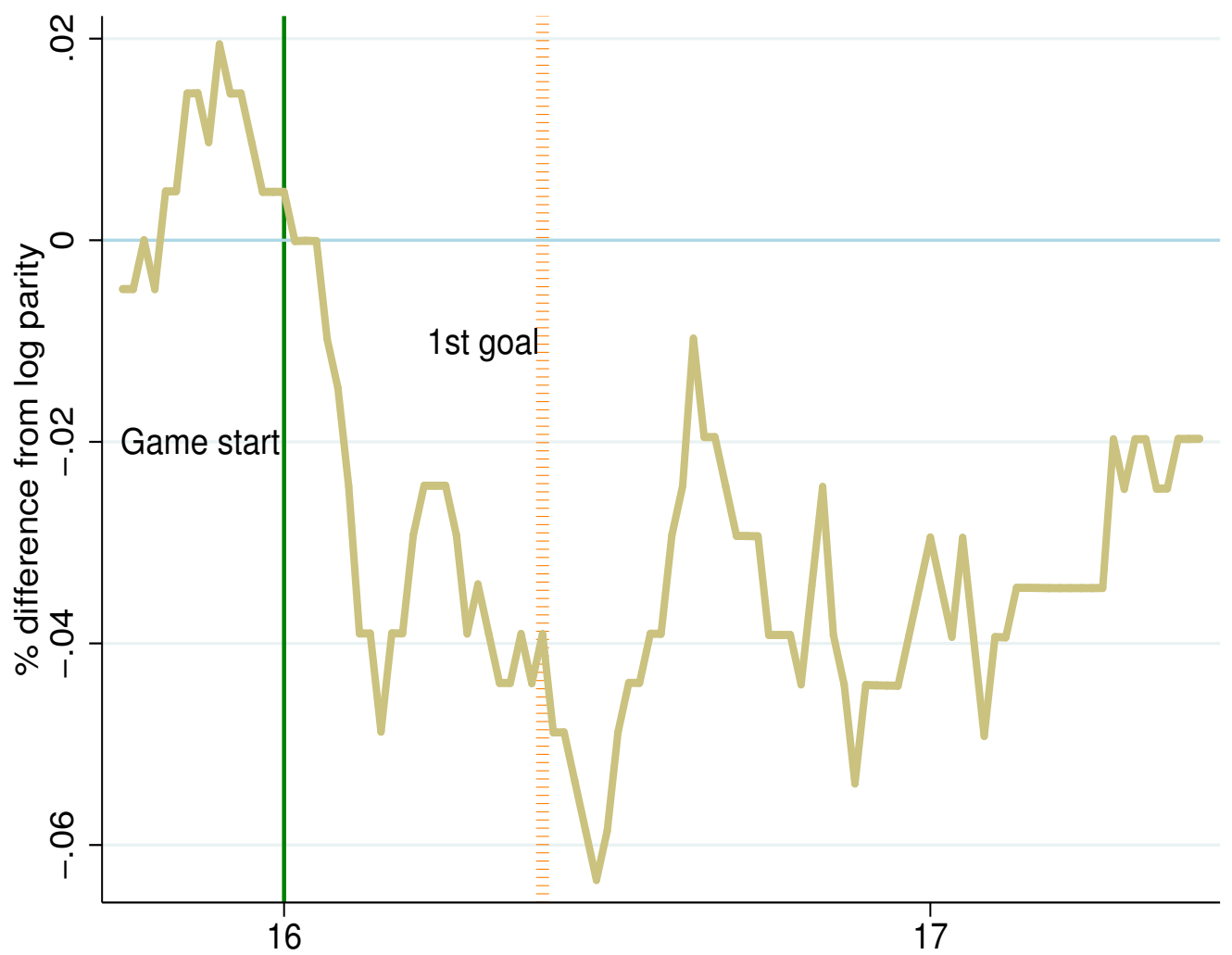

Notes: This figure shows percentage deviations from log parity between prices for STMicroelectronics on the Milan and Paris stock exchanges. We show 15-minute moving averages for $P D_{t}^{I}$ (equation 2) during the soccer match between Slovakia and Italy on 24 June 2010 at the FIFA World Cup. The horizontal axis shows the period between 15:45 and 17:30. The solid vertical line denotes the start of the game at 16:00. The dotted vertical line denotes the first goal by Slovakia. 
Figure 4: Price deviations: Distribution during and outside matches
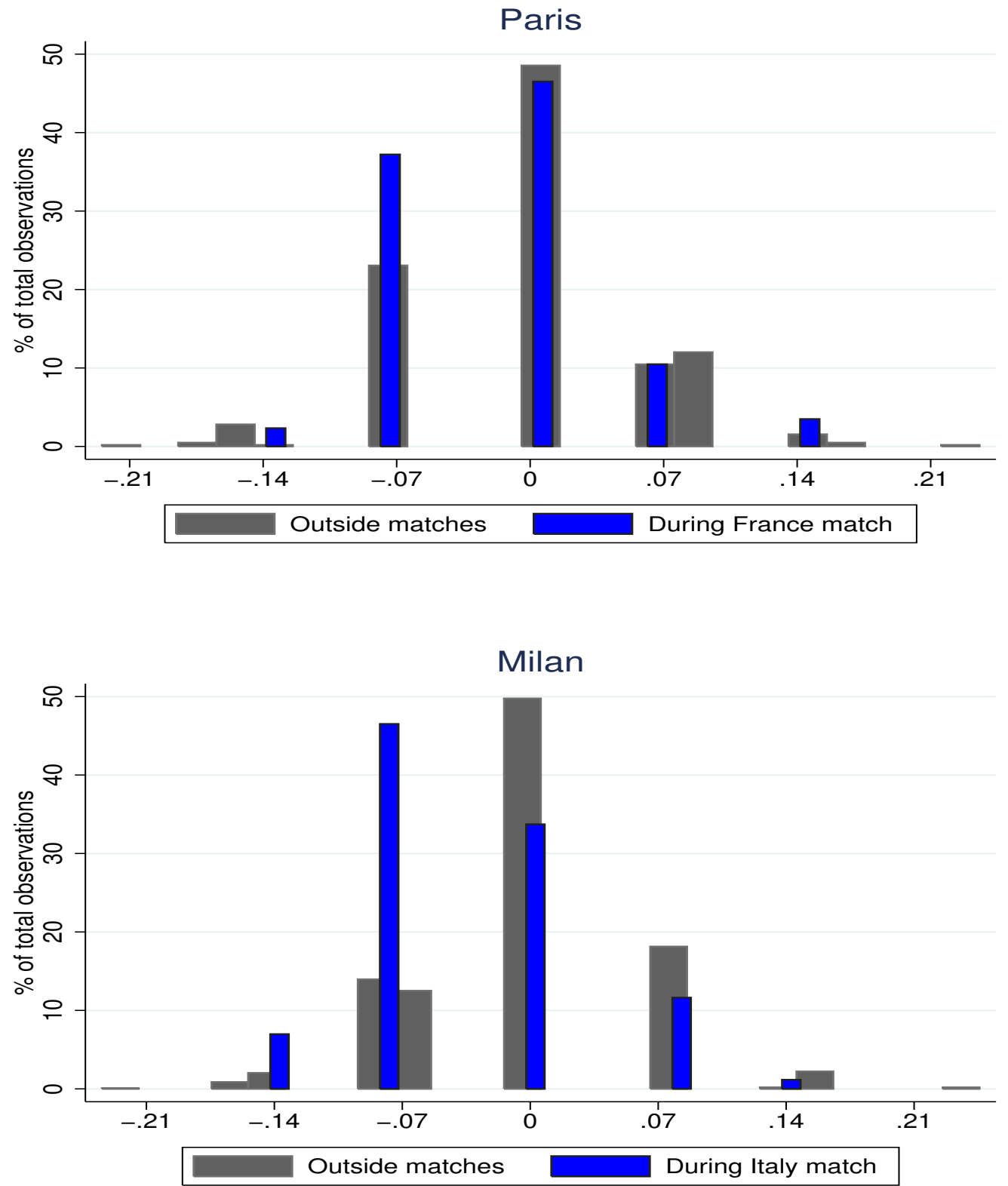

Notes: The histograms summarize pricing deviations for STMicroelectronics during (dark bars) and outside (grey bars) the soccer matches. The top panel shows results for pricing deviations in Paris (following equation 1); the bottom panel has results for deviations in Milan (following equation 2). The control sample covers a time period from 3 May 2010 to 30 July 2010, where we exclude the time frames of the matches between South Africa and France (22 June), and Slovakia and Italy (24 June). For France, the control sample uses only observations on Tuesdays after 16:00. For Italy, the control sample uses only observations on Thursdays, also after 16:00. The vertical axis shows the percentage of the total number of observations. 
Figure 5: Placebo sample: One day before matches
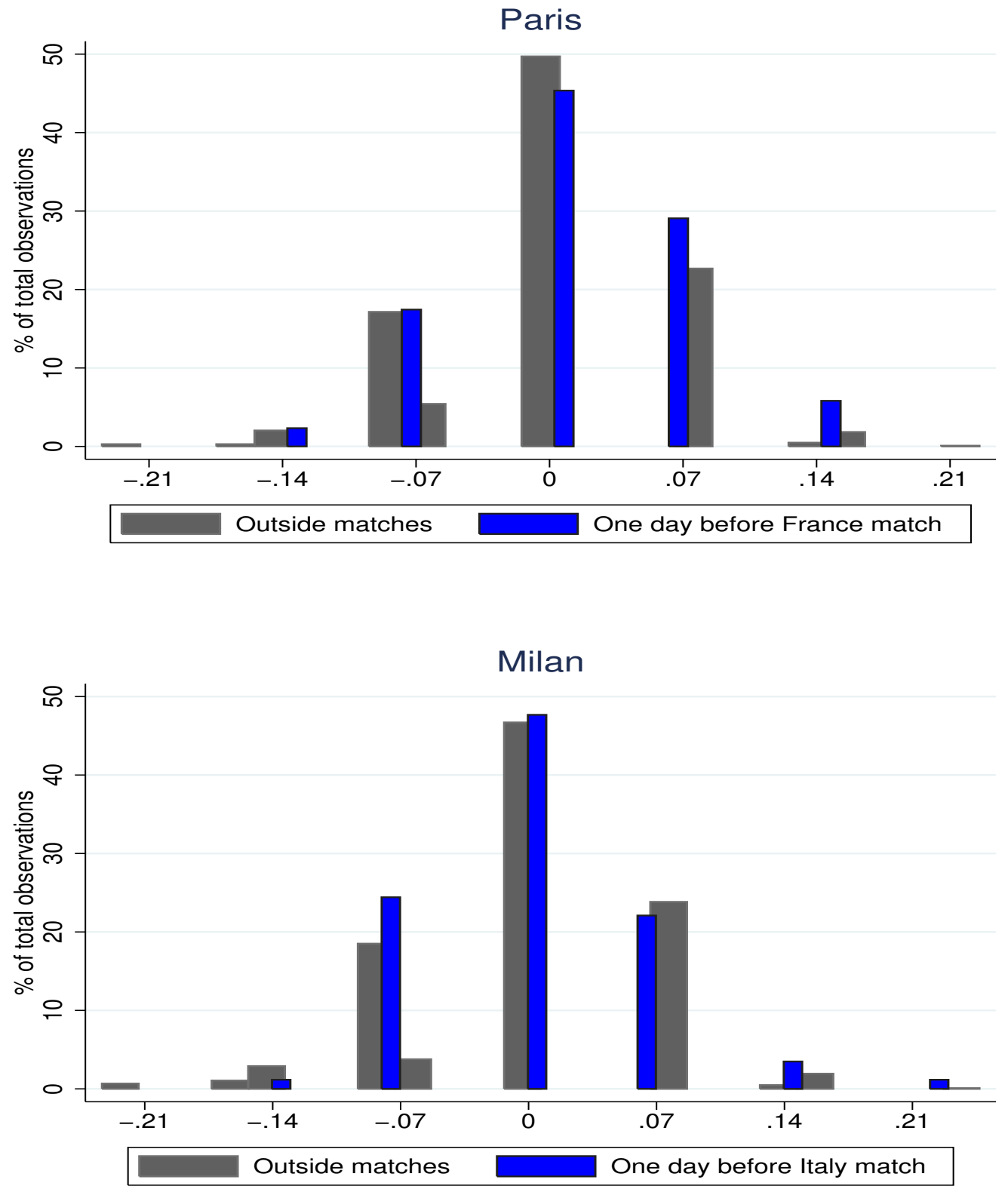

Notes: The histograms summarize pricing deviations for STMicroelectronics during a placebo sample based on the same time slot as the matches, but one day before the matches took place (dark bars) and during a control sample outside the time of the matches (grey bars). The top panel shows results for pricing deviations in Paris (following equation 1); the bottom panel shows results for deviations in Milan (following equation 2). The control sample covers a time period from 3 May 2010 to 30 July 2010. For France, the control sample uses only observations on Mondays after 16:00. For Italy, the control sample uses only observations on Wednesdays, also after 16:00. The vertical axis shows the percentage of the total number of observations. 
Table 1: Mood effects during South Africa-France match

\begin{tabular}{|c|c|c|c|c|c|}
\hline & $(1)$ & $(2)$ & (3) & $(4)$ & $(5)$ \\
\hline Underpricing & & & & & \\
\hline During match & $\begin{array}{l}0.124^{* *} \\
(0.046)\end{array}$ & $\begin{array}{l}0.127^{* *} \\
(0.046)\end{array}$ & $\begin{array}{l}0.128^{* *} \\
(0.046)\end{array}$ & & \\
\hline Pre game & & $\begin{array}{l}-0.022 \\
(0.116)\end{array}$ & $\begin{array}{l}-0.020 \\
(0.116)\end{array}$ & $\begin{array}{l}-0.018 \\
(0.116)\end{array}$ & $\begin{array}{l}-0.020 \\
(0.116)\end{array}$ \\
\hline Post game 1 & & $\begin{array}{l}0.384^{* *} \\
(0.117)\end{array}$ & $\begin{array}{l}0.383^{* *} \\
(0.117)\end{array}$ & $\begin{array}{l}0.385^{* *} \\
(0.117)\end{array}$ & $\begin{array}{l}0.383^{* *} \\
(0.117)\end{array}$ \\
\hline Post game 2 & & $\begin{array}{c}0.055 \\
(0.109)\end{array}$ & $\begin{array}{c}0.054 \\
(0.109)\end{array}$ & $\begin{array}{c}0.055 \\
(0.109)\end{array}$ & $\begin{array}{c}0.054 \\
(0.109)\end{array}$ \\
\hline Number of trades Paris & & & $\begin{array}{c}0.053^{*} \\
(0.024)\end{array}$ & $\begin{array}{c}0.054^{*} \\
(0.024)\end{array}$ & $\begin{array}{c}0.053^{*} \\
(0.024)\end{array}$ \\
\hline Number of trades Milan & & & $\begin{array}{c}-0.050^{*} \\
(0.022)\end{array}$ & $\begin{array}{c}-0.050^{*} \\
(0.022)\end{array}$ & $\begin{array}{c}-0.050^{*} \\
(0.022)\end{array}$ \\
\hline Minutes into game & & & & $\begin{array}{l}0.004^{* *} \\
(0.001)\end{array}$ & \\
\hline Game tied & & & & & $\begin{array}{l}-0.220 \\
(0.123)\end{array}$ \\
\hline Team trailing & & & & & $\begin{array}{l}0.202^{* *} \\
(0.051)\end{array}$ \\
\hline Pseudo R-squared & 0.02 & 0.02 & 0.02 & 0.02 & 0.02 \\
\hline Log likelihood & -18641 & -18635 & -18632 & -18626 & -18626 \\
\hline Chi-squared & 780.4 & 789.8 & 795.9 & 806.3 & 807.7 \\
\hline p-value & 0.00 & 0.00 & 0.00 & 0.00 & 0.00 \\
\hline Observations & 32570 & 32570 & 32570 & 32570 & 32570 \\
\hline
\end{tabular}

Notes: Average marginal effects and robust standard errors (in parentheses) based on probit regressions.

Sample period: 3 May - 30 July 2010, excluding the time frame of the soccer match between Slovakia and Italy. The dependent variable is a $(0,1)$ dummy that equals one when the prices for STMicroelectronics are lower on the Paris stock exchange than on the Milan exchange and equals zero otherwise. The "Pre game" variable equals 1 during the 15 minutes before the match between South Africa and France; "Post game 1" equals 1 in the first 15 minutes of the trading day after the match; "Post game 2" equals 1 for the second 15 minutes of the trading day after the match; "Number of trades" are measured per 100 per minute; "Game tied" equals 1 while the teams are tied; "Team trailing" equals 1 when France is trailing. All regressions include dummies capturing month, week, day-of-the-week and time-of-day effects. * and ** denote significance at the $5 \%$ and $1 \%$ level, respectively. 
Table 2: Mood effects during Slovakia-Italy match

\begin{tabular}{|c|c|c|c|c|c|}
\hline & (1) & (2) & $(3)$ & $(4)$ & $(5)$ \\
\hline Underpricing & & & & & \\
\hline During match & $\begin{array}{l}0.226^{* *} \\
(0.047)\end{array}$ & $\begin{array}{l}0.226^{* *} \\
(0.047)\end{array}$ & $\begin{array}{l}0.231^{* *} \\
(0.047)\end{array}$ & & \\
\hline Pre game & & $\begin{array}{c}0.050 \\
(0.111)\end{array}$ & $\begin{array}{c}0.052 \\
(0.111)\end{array}$ & $\begin{array}{c}0.049 \\
(0.111)\end{array}$ & $\begin{array}{c}0.052 \\
(0.111)\end{array}$ \\
\hline Post game 1 & & $\begin{array}{l}-0.052 \\
(0.121)\end{array}$ & $\begin{array}{l}-0.053 \\
(0.121)\end{array}$ & $\begin{array}{l}-0.053 \\
(0.121)\end{array}$ & $\begin{array}{l}-0.053 \\
(0.121)\end{array}$ \\
\hline Post game 2 & & $\begin{array}{l}-0.014 \\
(0.117)\end{array}$ & $\begin{array}{l}-0.015 \\
(0.117)\end{array}$ & $\begin{array}{l}-0.015 \\
(0.117)\end{array}$ & $\begin{array}{l}-0.015 \\
(0.117)\end{array}$ \\
\hline Number of trades Paris & & & $\begin{array}{c}-0.060^{*} \\
(0.025)\end{array}$ & $\begin{array}{c}-0.057^{*} \\
(0.025)\end{array}$ & $\begin{array}{c}-0.060^{*} \\
(0.025)\end{array}$ \\
\hline Number of trades Milan & & & $\begin{array}{c}0.046^{*} \\
(0.023)\end{array}$ & $\begin{array}{c}0.044 \\
(0.023)\end{array}$ & $\begin{array}{c}0.047^{*} \\
(0.023)\end{array}$ \\
\hline Minutes into game & & & & $\begin{array}{l}0.004^{* *} \\
(0.001)\end{array}$ & \\
\hline Game tied & & & & & $\begin{array}{l}0.276^{* *} \\
(0.086)\end{array}$ \\
\hline Team trailing & & & & & $\begin{array}{l}0.214^{* *} \\
(0.055)\end{array}$ \\
\hline Pseudo R-squared & 0.02 & 0.02 & 0.02 & 0.02 & 0.02 \\
\hline Log likelihood & -19129 & -19129 & -19126 & -19129 & -19125 \\
\hline Chi-squared & 721.4 & 721.8 & 727.3 & 720.0 & 727.8 \\
\hline p-value & 0.00 & 0.00 & 0.00 & 0.00 & 0.00 \\
\hline Observations & 32568 & 32568 & 32568 & 32568 & 32568 \\
\hline
\end{tabular}

Notes: Average marginal effects and robust standard errors (in parentheses) based on probit regressions.

Sample period: 3 May-30 July 2010, excluding the time frame of the soccer match between South Africa and

France. The dependent variable is a $(0,1)$ dummy that equals one when the prices for STMicroelectronics are lower on the Milan stock exchange than on the Paris exchange and equals zero otherwise. The "Pre game" variable equals 1 during the 15 minutes before the match between Slovakia and Italy; "Post game 1" equals 1 in the first 15 minutes of the trading day after the match; "Post game 2" equals 1 for the second 15 minutes of the trading day after the match; "Number of trades" are measured per 100 per minute; "Game tied" equals 1 while the teams are tied; "Team trailing” equals 1 when Italy is trailing. All regressions include dummies capturing month, week, day-of-the-week and time-of-day effects. * and ** denote significance at the $5 \%$ and $1 \%$ level, respectively. 
Table 3: Probability of underpricing during three placebo samples

\begin{tabular}{|c|c|c|c|}
\hline Panel A: Paris exchange & $(1)$ & $(2)$ & $(3)$ \\
\hline $\begin{array}{l}\text { Underpricing } \\
\text { Placebo } 1 \text { day earlier }\end{array}$ & $\begin{array}{l}-0.029 \\
(0.051)\end{array}$ & & \\
\hline Placebo 1 week later & & $\begin{array}{c}0.011 \\
(0.047)\end{array}$ & \\
\hline Placebo 1 week earlier & & & $\begin{array}{l}-0.050 \\
(0.049)\end{array}$ \\
\hline $\begin{array}{l}\text { Pseudo R-squared } \\
\text { Log likelihood } \\
\text { Chi-squared } \\
\text { p-value } \\
\text { Observations }\end{array}$ & $\begin{array}{c}0.02 \\
-18583 \\
775.0 \\
0.00 \\
32484 \\
\end{array}$ & $\begin{array}{c}0.02 \\
-18583 \\
774.6 \\
0.00 \\
32484 \\
\end{array}$ & $\begin{array}{c}0.02 \\
-18583 \\
775.8 \\
0.00 \\
32484 \\
\end{array}$ \\
\hline Panel B: Milan exchange & $(1)$ & $(2)$ & $(3)$ \\
\hline $\begin{array}{l}\text { Underpricing } \\
\text { Placebo } 1 \text { day earlier }\end{array}$ & $\begin{array}{c}0.001 \\
(0.051)\end{array}$ & & \\
\hline Placebo 1 week later & & $\begin{array}{l}0.110^{*} \\
(0.053)\end{array}$ & \\
\hline Placebo 1 week earlier & & & $\begin{array}{c}0.044 \\
(0.049)\end{array}$ \\
\hline $\begin{array}{l}\text { Pseudo R-squared } \\
\text { Log likelihood } \\
\text { Chi-squared } \\
\text { p-value } \\
\text { Observations }\end{array}$ & $\begin{array}{c}0.02 \\
-19070 \\
697.9 \\
0.00 \\
32482\end{array}$ & $\begin{array}{c}0.02 \\
-19068 \\
701.8 \\
0.00 \\
32482\end{array}$ & $\begin{array}{c}0.02 \\
-19070 \\
698.7 \\
0.00 \\
32482\end{array}$ \\
\hline
\end{tabular}

Notes: Average marginal effects and robust standard errors (in parentheses) based on probit regressions. We report results for three placebo samples, where we assume that matches took place one day earlier (column 1), one week later (column 2) or one week earlier (column 3). Panel A shows results for the Paris stock exchange; panel B shows results from the perspective of the Milan exchange. Sample period: 3 May-30 July 2010, excluding the actual time of the South Africa versus France and Slovakia versus Italy matches. The coefficients can be compared with those in column 1 of tables 1 and 2. All regressions include dummies capturing month, week, day-of-the-week and time-of-day effects. ${ }^{*}$ and ${ }^{* *}$ denote significance at the $5 \%$ and 